\title{
PROSPECTS FOR THE DEVELOPMENT OF SUSTAINABLE ENTREPRENEURSHIP IN LATVIA.
}

Kristine Blumfelde-Rutka ${ }^{1}$, Mg.soc.zin.;

\author{
${ }^{1}$ Riga Stradins University
}

\begin{abstract}
A prominent business topic of nowadays in the context of sustainability is balanced economic management one that contributes to economic development, environmental protection and public wellbeing. Given the positive growth potential of the European market for sustainable entrepreneurship and the improvement of Latvia's environmental sustainability in the entrepreneurship sector, it is important to find out the prospects of further development of sustainable entrepreneurship in Latvia. The aim of the research is to define sustainability in the context of business, to identify the factors that motivate and determine the sustainability of the company and to evaluate sustainable business perspectives in Latvia. Hence, the process of business management has to provide for interaction among the company, the management and utilisation of its resources, its financial management, and the stakeholders of the buying and selling process - businesses, consumers and public authorities. In light of the above, business management can not only contribute to a sustainable product consumption but also make a positive impact upon public action and thinking. The author's research fields conclusions regarding the key factors for running a sustainable business in Latvia. Based on expert interviews, it was analysed what promotes / hampers the development of sustainable entrepreneurship in Latvia, looking into the prospects of sustainable entrepreneurship in Latvia. During the research it was found, that the development of sustainable entrepreneurship in Latvia is promoted by the regulatory pressure created by the European Union, as well as the growing public interest in sustainability issues created by the available information space. The development of sustainable entrepreneurship in Latvia is hindered by the lack of interaction between public education and the regulatory system in terms of sustainability, reducing the effectiveness of motivating sustainable choices.
\end{abstract}

Key words: sustainability; sustainable development; sustainable entrepreneurship; corporate responsibility, climate neutrality.

JEL code: M14; M31

\section{Introduction}

Sustainable entrepreneurship revolves around a number of factors: resource management (including water and energy use, waste production, generation of GHG and other emissions), financial management (innovative capacity, CEO-to-average employee pay ratio), personnel management (employee turnover, clean revenue - the percentage of total revenue generated from ecological products and services), as well as the operational and strategic processes within the company.

Purpose of the article: to define sustainability in the context of business, to identify the factors that motivate and determine the sustainability of the company and to evaluate sustainable business perspectives in Latvia, based on an analysis of scientific literature, secondary data and expert opinions. Object of the research - sustainable entrepreneurship. Subject of the research - the impact of sustainable entrepreneurship upon public action and thinking.

Methodology/methods: using scientific databases, fundamental literature is embedded in this study as well as contemporary scientific research. This research includes secondary and primary research methods. The research used the results of the author's previous studies and there were expert interviews conducted to assess the prospects of sustainable entrepreneurship in Latvia. Qualitative research method was used expert interviews, the opinions and recommendations of five independent experts were obtained, the representatives were selected from among both the academic and the business fields. Interviews with experts in the domain of sustainability (representatives of entrepreneurship, the academic environment, fashion, marketing, manufacturing companies and specialists from the institute for sustainable development) conducted in 2020. The experts answered a total of seven questions, which include the 
definition of sustainable business, the impact of societal norms and consumer buying trends, motivating factors, the sustainability of the most developed and promising industries, and recommendations for entrepreneurs and government.

\section{The importance of sustainable entrepreneurship}

Scientific literature increasingly emphasises the key role of sustainability in the development of enterprises and the challenge of building business management systems and, thus, creating consumer needs.

Sustainable entrepreneurship encompasses the ability to use resource-preserving methods, factoring in the nature neutrality level and keeping it unchanged in the long run. The International Institute for Sustainable Development (IISD, 2015) has put forward a definition of sustainable development - it is a development that meets the needs of the present without compromising the ability of future generations to meet their needs. Importantly in the context of sustainable entrepreneurship, sustainable development of businesses envisages ensuring that the present and future needs be satisfied. Sustainable entrepreneurship is based on preserving nature, life supply and society with a view to enable the creation of future products, processes and services, giving economic and non-economic benefits to individuals, the public, and the economy as a whole (Shephard D. A., Patzelt H., 2011). In the present situation, the operation of businesses needs a sustainability direction, which is necessitated by the expansion of public thinking resulting from the development of science and information technologies available. Specifically, it is the idea of importance of optimum use and preservation of resources that impacts the present and will impact the future generations' lifetime and drives the need for sustainability prescribed by the market. The need for sustainable entrepreneurship is explained as the process of discovery, assessment and utilisation of economic opportunities through market imperfections (Dean T. J., McMullen J. S.,2017). For instance, searching for economic opportunities using market imperfections is consolidated by creating social and natural benefits for the public whilst also ensuring that the future society be able to satisfy its needs (Greco A., de Jong G., 2017). However, the possibility of identifying the needs of future generations is low, since historically the rate of growth and development experienced by society has been rapid.

With the importance of sustainability primarily manifesting itself in adaptability, entrepreneurs' motivation to act sustainably when choosing between profit and goal comes to the forefront. Sustainable entrepreneurship envisages companies' work to be motivated by and processes to be driven towards prosperity. Entrepreneurship and sustainability as separate notions require innovation and together those yield a creative combination of available resources. Entrepreneurship and sustainability innovation are entrepreneurship with a cause and a purpose, transforming the company's operation from being part of the problem to being part of the solution (Abrahamson A., 2008). This approach represents: 1) focusing on some of the global, social or sustainability problems, 2) by finding, identifying or creating a solution and introducing the innovation in the market, and thus 3) creating or deeply transforming an existing company, promoting it as a mission- or cause-oriented sustainable business, adding economic, ecological or social values and benefits through dematerialisation.

In sustainability-driven entrepreneurship one can distinguish between two types of entrepreneurship which both feature innovation, creative expression and business functionality yet differ in terms of motivation, purpose, economic and non-market objectives, growth challenges and potential. Specifically, the essence of eco-preneurship lies in innovative activities, with environmental aspects as priority and competitiveness as advantage. Eco-preneurship is based on identifying ecological innovations, determining their market potential, and implementing them in the market. There are thus two types of entrepreneurship 
in terms of motivation: 1) for-profit companies (ecopreneurial corporations who use ecological products and processes for the utmost personal benefit); 2) social ecopreneurs (companies who work towards promoting ecologically beneficial ideas, products, technologies through market or non-market channels). Overall, the objective of ecopreneurs is to profit from the solution of environmental issues, which involves dealing with ecological challenges and creating added value.

In social entrepreneurship, the motivation stems from the need to solve social problems and lies in the generation of profit for public needs. The attainment of the social purpose and the securing of financing are set as the main objectives. Social entrepreneurship creates innovations with a view to change the public thinking and action and give benefits to the public in general. Hence, the success of such business is measured not by profit or turnover but by progress and impact in terms of public benefit.

The motives behind the choice of working principles of sustainability differ from company to company. They are based on the company's sector, size, goal and values. One motivation of pursuing sustainable entrepreneurship manifests itself in creating a vision, identifying the resources needed, and using them to put the vision into effect. Thus, the individual commitment to solving environmental problems results in a three-dimensional understanding of causes: affective (emotional cause), growth continuation (economic and social cause) and regulatory cause (Leno M.J., 2011). Such ideas lead to a conclusion that the motivation for sustainable entrepreneurship lies in the implementation of the company's core vision and values based on adherence to the purpose of its foundation and meeting the stakeholder and consumer needs and the regulatory requirements. A key motivator of sustainability is effective attraction of investment. In light of the global tendencies of moving towards sustainable economy, the consideration of sustainability is a criterion widely used in deciding upon investments. Motivational factors of sustainability can be divided as follows: 1) internal factors of the company (internal beliefs, concern for social and environmental issues) and 2) external factors (market imperfections, networking, social capital and public acceptance). A key role in the motivation of small and medium enterprises is typically played by the company's attitude towards and knowledge on sustainability, adherence to social norms as a result of public pressure and building a positive image of itself (attraction of positive associations) (Greco A., Jong G., 2017). The idea of treating a profit-making business and a sustainable business as opposites has been a common practice throughout the development of the concept of sustainability, with sustainability believed to require funds without a result in return, but nowadays there is an interplay of environmental, social and profit factors in business. The causes of motivation for sustainable entrepreneurship are the regulatory framework (the regulatory aspect), the public views, the expected competitive advantage and the senior management commitments (Gast et.al., 2017). The external stakeholders - the legislators and the public - are an effective means to drive a company's sustainability, but companies mainly respond to these external forces by drawing up and implementing environmental strategies for their business. The expected competitive advantage is an internal and external driving force for the company's sustainability, one that stems from the management's conviction that the company can surpass competitors by implementing or improving an environmental strategy. The management's commitment towards implementing sustainability factors in the company's functioning needs to be planned in an efficient and controlled manner and effected by the management, and this is integrated long-term in the company's corporate strategy. In light of the increased global attention to sustainability over the last five years and the increased pressure upon natural resources and climate change along with an increase in deliberate consumption and ethical life, there are three major sustainability trends that make companies alter their operation across all industries and urge them to implement sustainability (from raw material and product manufacturers all the way to logistics companies and retailers). Businesses that operate in an ethical manner, pursue circular economy, and 
practice sustainable packaging can improve their brand image and reputation and draw more ethically oriented and demanding consumers. $61 \%$ of consumers take interest in climate change, 64\% believe that they can change something in the world through their purchases, and $51 \%$ trust companies' statements of sustainability (Euromonitor Lifestyles survey 2019), ethical lifestyle (factoring in environmental considerations in commercial and household decisions) is one of eight most common trends as per Euromonitor, $39 \%$ of consumers choose less products but of higher quality, $35 \%$ are willing to purchase recycled goods, while $28 \%$ are happy to buy ethical products.

Although the dynamics of the number of consumers choosing goods, products and services produced through sustainable business is positive, there is a gap between the consumers' wish to reduce their environmental impact and the actual buying decision. Effectiveness, value and aesthetics are still the main features sought for when choosing products. The high price of products that conform to the principles of sustainability and the lack of transparency and traceability throughout the supply chain at times prevent consumers from deciding, e.g., to purchase sustainable products or changing their housekeeping habits. Providing information and raising awareness of the origin, composition, transportation and manufacturing of products might make people willing to pay more for those products.

From the standpoint of sustainable marketing, previous pieces of research based on a survey of companies' leading specialists and buyers (a random sample of 1003 respondents) showed that businesses need to create a well-thought approach, a sustainable product assortment and promotion and selling activities in line with sustainability conditions. The consumers of nowadays are very sensitive to any price changes, and businesses may use price changes as marketing communication tool in communication with their consumers to help not only sell or promote new products, but also boost the sales of healthy, ecological, domestic manufactured products (Bormane S., 2018). It was also concluded that 1) value proposition may be directly related to product consumption value - quality, ingredients, the manufacturing process, sufficient information, including the re-use and utilisation of packaging, the need for products and the benefits from their use etc. ; 2) consumers lack information and competence on product characteristics, which businesses can raise by applying marketing communication - on packaging, labels, informational marking, thus boosting the consumption of sustainable products. ( Skiltere D., Bormane S., 2018)

The improvement of business in terms of adherence to a sustainable marketing concept relates not only to the product assortment, quality, packaging and design, but also to distribution and promotion, thus contributing to the formation of public opinion on the importance of environment conservation, the raising of consumer awareness, the enhancement of corporate social responsibility for consumer health, ecological products overall, and the role and contribution of a green economy to the country's economy as a whole (Bormane S., 2018)

In order to reach the company's goals in communication with consumers, the marketing communication must be implemented through specific, customer-oriented tools for sustainability to increase the consumption value of a product or service for sustainability - economic development, public well-being, and environment preservation ( Skiltere D., Bormane S., 2018).

In order to avoid greenwashing, the entire business process needs to be aimed towards sustainable development: incorporating innovations in products, services and processes alike, i.e., creating: 1) a value proposition and supply chain, interfacing with customers, 2) a financial model. This highlights the contributing and hindering factors for sustainable entrepreneurship, as well its prospects of development. 


\section{Research results and discussion}

Subsequently, in order to assess sustainable entrepreneurship in Latvia, the authors employed a qualitative research method - interviews with experts in the domain of sustainability (representatives of entrepreneurship, the academic environment, fashion, marketing, manufacturing companies and specialists from the institute for sustainable development) conducted in 2020.

The expert opinion and suggestions make it possible to identify the key aspects that cause both favourable and adverse conditions for sustainable development - i.e., the impact of social norms and consumer purchase trends, motivational factors, the more developed and promising sectors in the context of sustainability - and to give recommendations to entrepreneurs and the government.

In Latvia, renewable sources of energy cover $40 \%$ of the country's energy needs, which is one of the highest shares among the OECD countries. Yet, despite the progress, the state needs to do more towards the development of sustainable growth. The residential sector is the main energy consumer in Latvia, followed by transport which is also the main source of GHG emissions and air pollution.

When it comes to developing sustainable entrepreneurship, there are three main directions environment, vital resources and communities where: 1) environmental protection encompasses biodiversity, ecosystems and natural landscapes; 2) vital resources refer to nature as a whole, natural resources and opportunities presented by ecosystems: the preservation of resources that are essential to the survival of humanity, such as clean air, water, environmental accessibility etc.; 3) communities are a network of individuals with common values, norms, history and identity so that, if the culture, groups of people or geographical locations are under threat, the communities may be broken up. Culture is a central aspect of society - maintaining the expression of a unique culture in a wider public maintains the identity of an individual which is crucial to the functioning of society (McMullen J.S, 2017). These factors are what sustainability mostly relies on, and opportunities arise in the development and application of these directions at a given company, contributing to long-term importance in one or multiple aspects of sustainability.

Entrepreneur-oriented recommendations can be used both for the transformation of an existing company into compliance with the principles of sustainability and for the creation of a new company focused on sustainability. For the sustainable development of the company, it is necessary to draw consumers' attention to the impact and consequences of choosing sustainable products, thus emotionally creating consumer awareness and desire to reduce negative environmental and social impact, provide consumers with information about the impact of the purchase decision. It is possible to use sustainable activity as a tool of reputation, but by proving it with the work done, to create a company's sustainability goal and develop principles, that the parties involved must also meet the specific sustainability criteria. It is important to experiment and focus not only on one, but to work with different tools to achieve sustainable operations (both product production, raw material extraction, product packaging, internal business process management and operation, and other areas of the company's operations). At the beginning of a company's sustainable development, it is important to understand and learn to start with minimal investment, perform activities that do not require financial resources, start with a small optimization of daily activities, selection of electronic solutions and other resource-saving means). An important factor is to start with the organization of the company's system - to make the system as digital as possible, including order acceptance, marketing, automatic answers, invoice generation, document management and other functions, because daily processes and work account for the largest consumption of time, pay and resources. The operation must be systematic in order to build consumer connectivity and confidence that 
the business is stable and efficient in the long run. Before starting a sustainable business, it is also necessary to understand your personal thoughts, issues and values, thus understanding whether the entrepreneur is really ready to enter this sustainable business market, it is important to understand how the company has the greatest impact in the current or potential case. In addition, it is possible to form partnerships with suppliers and other companies, effectively combine sustainability with open innovation, focusing on cooperation, use a circular strategy, ensuring that the activities of cooperation partners and suppliers are also in line with sustainability. In general, it is important to introduce innovative ways in all aspects of business to promote sustainable development.

A number of directions have been set forth for sustainable development in Latvia: cultural space development, investment in human capital, change of paradigm in education, promotion of innovative and efficient economy, treating nature as future capital, observance of spatial development prospects, innovative governance, and public participation. Social norms and consumer purchase trends contribute favourably to the development of sustainable entrepreneurship in Latvia, but to a limited extent for now, which is why building consumer awareness for evaluating the long-term benefit and a change of consumer lifestyle and purchase trends towards sustainability is important. According to the experts, currently the most advanced industries in terms of implementing the principles of sustainability are energy, forestry, agriculture and the banking sector, also the food industry due to the plastic packaging used, as well as the industries with more environmental and human impact, such as the financial sector and transport. Hence, it matters what decisions the companies of these sectors make and what projects or initiatives they fund and support.

According to the experts, when it comes to the development of sustainability, Latvia needs improvements in transport infrastructure, energy efficiency and renewable energy diversity in terms of better profitability of public spending, reduced dependency on EU funds, and enhanced financial support for investments in business environment. The experts named educational programmes, standards and requirements, product labelling regulations, special tax conditions (for natural resource tax, individual income tax), public availability of studies, reports and open access information, and state and municipal procurement requirements incorporating the principles of sustainability as the main instruments towards sustainable development on a state level.

\section{Conclusions, proposals, recommendations}

\section{The results of the research are of both theoretical and practical value.}

\section{Conclusions:}

1) The development of sustainable entrepreneurship in Latvia is propelled by the regulatory pressure exerted by the European Union, as well as the increasing public interest in sustainability matters aroused by the available informational space.

2) The importance of sustainability in entrepreneurship manifests itself in companies' adaptability and motivation when choosing between profit and goal and envisaging their work as advancement towards prosperity. Sustainable entrepreneurship requires innovation, and together they make a creative combination of available resources.

3) In light of the global tendencies in terms of sustainable economy, a key motivator for business reorientation towards adherence to the principles of sustainability is effective attraction of investment, implementation of innovations, change of management process, adaptation of corporate strategy, 
considering such factors as concern for social and environmental problems, market imperfections, social capital, and public capability and willingness to accept changes.

4) Social norms and consumer purchase trends contribute favourably to the development of sustainable entrepreneurship in Latvia, but it is important to build the awareness of consumers as members of the public for the evaluation of the long-term benefit and to change people's lifestyle and purchase trends towards sustainability.

5) Industries that are major impact makers - energy, forestry, agriculture, the banking sector, food production, the financial sector and transport - possess a high potential of promoting sustainability.

6) When it comes to promoting sustainability and implementing sustainable entrepreneurship in Latvia, there are improvements to be made in transport infrastructure, energy efficiency and renewable energy diversity, profitability of public spending, reducing dependency on EU funds and enhancing financial support for investments in business environment.

\section{Proposals, recommendations}

7) The key instruments for the promotion of sustainable entrepreneurship in Latvia are educational programme supply, improvement of standards, requirements and regulations to incorporate the principles of sustainability, special conditions for the application of natural resource tax, individual income tax, social tax, public availability of studies, reports and open access information, requirements of state and municipal procurements.

8) There are in-depth studies of consumers needed that would reveal the emergence of a need for sustainable products and the factors in favour of buying sustainable products.

9) The main tools for the development of sustainability from the state level - educational programs, regulations and requirements, regulations on product labelling, tax rebates (natural resources tax, personal income tax, social tax), studies, reports and open access information to the public, procurement tenders and their sustainable requirements.

10) The development of sustainable entrepreneurship in Latvia is hampered by insufficient interplay between the public awareness and the regulatory system from a sustainability perspective, reducing the effectiveness of motivation towards sustainable choices.

\section{Bibliography}

1. Bormane S. (2018). "Price as an Integrated Marketing Communications Tool in Promoting the Consumption of Sustainable Products", CBU International Conference Proceedings 2018, 2018, Volume 6, pp. 62-68

2. Bormane S., "Integrated Marketing Communications in Sustainable Business", Proceedings of the International Scientific Conference "Society. Integration. Education", 2018, Volume 6, pp. 80-96

3. Dean, T., J., McMullen, J., S. (2017). Toward a Theory of Ssustainable Eentrepreneurship: Reducing Environmental Degradation Tthrough Entrepreneurial Action. Boudler: University of Colorado Boulder, pp. 58140.

4. Euromonitor Lifestyles Survey 2019.

5. Gast, J., Gundolf, K., Cesinger, B. (2017). Doing Business in a Green Way: A Systematic Review of the Ecological Sustainability Entrepreneurship Literature and Future Research Directions. Montpellier: Montpellier Business School, pp. 46.

6. Greco, A., Jong, G. (2017). Sustainable Entrepreneurship: Definitions, Themes and Research Gaps. Groningen: University of Groningen, pp. 14-18.

7. The International Institute for Sustainable Development. 2015.

8. Lenox, M., York, J. 2012. Environmental Entrepreneurship. Boulder: University of Colorado Boulder

9. Robles, M. C. 21.06.2019. Business Sustainability Game Changers. Euromonitor International. Available from: https://blog.euromonitor.com/business-sustainability-game-changers [21.10.2020.]

10. Schaltegger, S., Wagner, M. (2010). Sustainable Entrepreneurship and Sustainability Innovation: Categories and Interactions. Leuneburg: Leuphana University of Leuneburg, pp. 224.

11. Shepherd, D. A., Patzelt, H. (2011). The New Field of Sustainable Entrepreneurship: Studying Entrepreneurial Action Linking "What Is to Be Sustained" With "What Is to Be Developed". Waco: Baylord University, pp. 142. 
12. Sustainable Development. (2020) Retrieved: https://www.iisd.org/about-iisd/sustainable-development

13. Skiltere D., Bormane S., "The Influence of Integrated Marketing Communications on the Demand of Sustainable Products at Latvian Food Retail Chains", CBU International Conference Proceedings 2018, 2018, Volume 6, pp. 441-447

14. Skiltere D., Bormane S., "Integrated Marketing Communication as a Business Management Tool in the Context of Sustainable Development", International Scientific Journal "Open Economics", 2018, Volume 1, Issue 1, pp. 115-123 